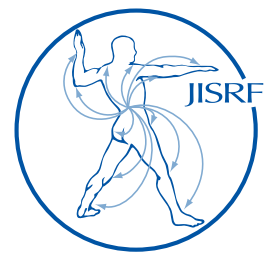

\title{
Prosthetic Hip Loosening Due to Brucellar Infection: Case Report and Literature Review
}

Tebourbi $A^{1}$, Hadhri $K^{2}$, Salah $M^{2}$, Bouzidi ${ }^{1}$, Kooli $M^{2}$

\section{Abstract}

Context: Brucellosis is actually considered to be the commonest zoonotic infection worldwide; conversely prosthetic infection due to brucella is extremely rare. Although diagnostic is easily achieved, management of such situations is extremely challenging.

Aims: To report the case of prosthetic hip loosening due to brucellar infection, discuss management manners and to summarize data about 19 cases reported in the literature.

Methods: We report the case of a 73-year-old woman with brucellar prosthetic hip loosening treated with 2-stage exchange of the prosthesis and prolonged double antibiotherapy

Results: At two years follow up the patient is pain free with total functional recovery and no clinical and radiographic signs of prosthetic loosening

Conclusions: Brucella should be evocated as a cause of total joint arthroplasty infection especially in patients from endemic regions and with occupational exposure. Antibiotic treatment alone can be followed if there are no signs of implant loosening. Tow stage revision should be considered in other cases

Keywords: total hip arthroplasty; prosthetic joint infection; Brucellosis

Level of Evidence: AAOS Therapeutic Level IV

\section{Introduction}

Brucellosis is now considered to be the commonest zoonotic infection worldwide with more than 500.000 new cases annually $[1, \underline{2}]$. According to the World Organization for Animal Health, North Africa has been traditionally considered endemic. Brucellosis affects several types of animals, including cows, sheep, goats, deer, pigs and dogs. Six species of gram-negative bacteria belonging to the genus Brucella are responsible for infection: B. melitensis, B. abortus , B. suis, B. canis, B. ovis, and B. neotomae. Only the first four are able to infect humans by ingestion of con-
1 Anis Tebourbi, Ramzi Bouzidi Department of Orthopedics and Traumatology, Mongi Slim Hospital, La Marsa, Tunisia

2 Khaled Hadhri, Mohamed Ben Salah, Mondher Kooli Department of Orthopedics and Traumatology, Charles Nicolle Hospital, Boulevard 9 Avril, 1006 Tunis, Tunisia

(Direct reprint requests to Khaled Hadhri)

(C) 2016 Tebourbi, Hadhri, Salah, Bouzidi, Kooli. All rights reserved. Authors retain copyright and grant the journal right of first publication with the work. Reconstructive Review follows the Creative Commons Attribution-NonCommercial CC BY-NC. This license

allows anyone to download works, build upon the material, and share them with others for non-commercial purposes as long as they credit the senior author, Reconstructive Review, and the Joint Implant Surgery \& Research Foundation (JISRF). An example credit would be: "Courtesy of (senior author's name), Reconstructive Review, JISRF, Chagrin Falls, Ohio". 
taminated food or drinks, inhalation of the organism, or inoculation through skin abrasion.

Osteoarticular infection is the most common complication and has been described with rates of $10 \%-85 \%$ in patients infected by brucella [3,4]. It affects the large joints, especially the sacro-iliac joint. Spondylitis, bursitis, tenosynovitis and osteomyelitis have been also described [ㅁ11].

Conversely prosthetic infection due to brucella is extremely rare. In the literature there are 19 cases of total joint arthroplasty infected by Brucella involving only 9 hips.

In the present report we describe a case of prosthetic hip loosening due to this infection and review the literature.

\section{Case Report}

73-year-old woman presented to our hospital in March 2002 with two years history of hip pain. After radiographic examination, the patient was diagnosed with osteoarthritis of the hip. The peripheral white blood cell (WBC) count was 5500 cells $/ \mathrm{mm} 3$, the erythrocytes sedimentation rate (ESR) was $50 \mathrm{~mm} / \mathrm{h}$, and the C-reactive protein (CRP) level was $4,8 \mathrm{mg} / \mathrm{l}$.

She underwent cemented Charnley total hip arthroplasty through a posterior approach. Culture of specimen from the synovium obtained during surgery was negative and microscopic examination showed degenerative changes.

The hip was pain free and annual postoperative radiographs were satisfactory until the 10th year.

On February 2012 the patient was hospitalized for L2L3 and T6-T7 brucellar spondylitis with discovertebral needle biopsy showing brucellar granuloma, positive Rose bengal test and 1/640 brucella serum antibody titer. She received standard chemotherapy with oral Doxyciline and Rifampicine.

In February 2014 the patient presented complaining of hip pain that had been present for the previous 8 months. There were no external signs of infection and no previous episod of fever. Radiographic examination showed evident signs of prosthetic loosening [Figure 1]. The inflammatory biomarkers included blood leukocytes count (8700cells/ $\mathrm{mm} 3)$ and C- reactive protein level $(7,6 \mathrm{ng} / \mathrm{l})$. A revision total hip arthroplasty (THA) was planned because of suspected asceptic loosening.

During the surgical procedure, purulent white fluid poured out of the joint with abundant necrotic tissue and marked loosening of the prosthesis.

At this stage revision total hip arthroplasty was abandoned and we proceed to resection arthroplasty through a

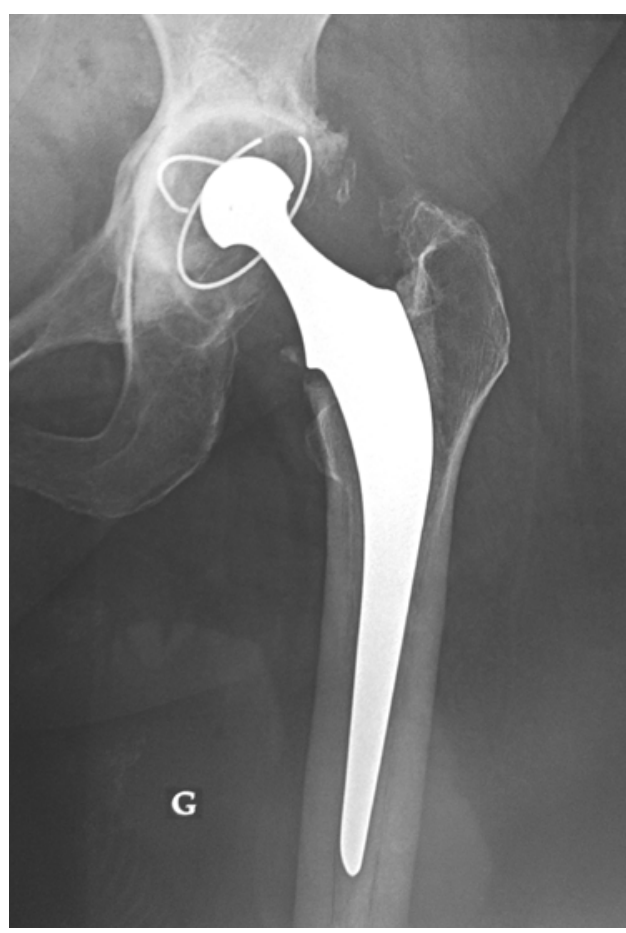

Fig. 1: Twelve year control $x$-ray demonstrating bipolar loosening of a total Charnley prosthesis of the left hip.

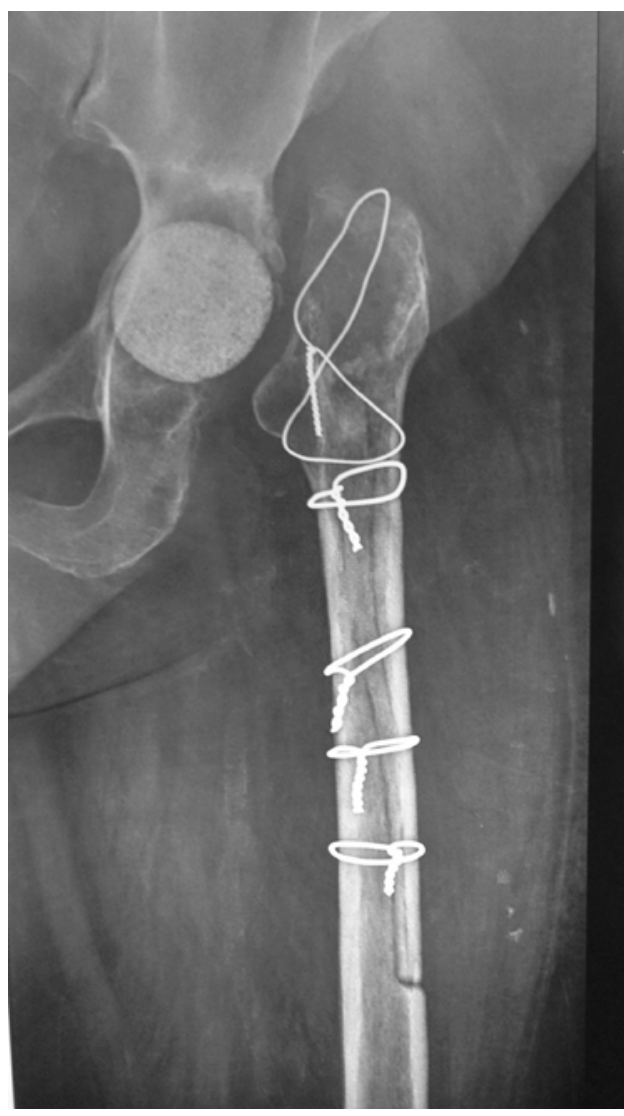

Fig. 2:

Postoperative control $x$-ray after femorortomy and prosthesis extraction.

large femorotomy [Figure 2] Several bacteriologic culture specimen and materials for pathologic examination were taken.

Empirical antibiotic treatment with Rifampicine $600 \mathrm{mg}$ and Ofloxacine 400 was started.

The bacteriological culture were negative but serum antibody titer for Brucella was $1 / 320$ and microscopic ex- 


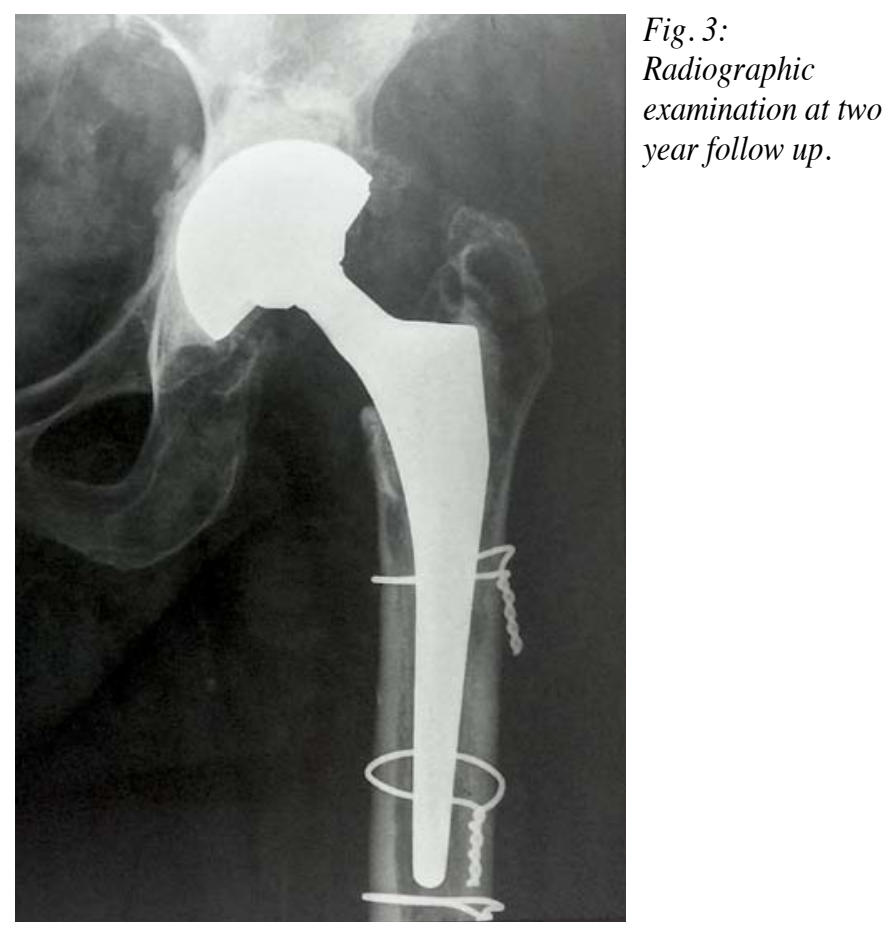

amination showed a brucellian granuloma. The antibiotic chemotherapy was maintained for 3 months, Ofloxacine wasn't changed because a history of digestive disagreement during the previous uses of Doxcycilline

A second stage of THA reimplantation was performed at the end of the antibiotic treatment period. At two years follow up the patient is pain free with total functional recovery and no clinical and radiographic signs of prosthetic loosening [Figure 3].

\section{Discussion}

Infection is considered to be the most devastating of prosthesis-related complication, leading to prolonged hospitalization, repeated surgical intervention. The incidence of prosthetic joint infection (PJI) is $1-2.5 \%$ for primary hip or knee replacements and $2.1-5.8 \%$ for revision surgeries [12-14].

The majority of infections (65\%) are caused by aerobic gram-positive cocci, most commonly Staphylococcus aureus, coagulase negative staphylococci and enterococci. Aerobic gram-negative bacilli, anaerobes and mycobacterial infection are far less frequent [15]. PJI due to Brucella is an extremely rare condition, and only 19 cases have been reported in the literature [16-28]. The demographic characteristics of the 19 cases and our patient are summarized in Table 1 [Table 1]. Among these patients, there were 12 men with a mean age of 59 years. Most patients had occupationnal exposure to brucella history of unpastorised milk products consumption and lived in areas where brucellosis is endemic. The Hip was involved in 10 patients. Knees were involved in 8 patients with two bilateral cases. Systemic symptoms of brucellosis as fever, headache, weakness, sweetness, profuse sweating, splenomegalia, adenopathy are non specific and were present in only four cases. Local symptoms as night pain, swelling, local inflammation, sinus tract formation and restriction of the joint movement were present in nearly all cases. Radiographic signs of loosening were found in nine cases. The rate of isolation of brucella in patients with osteoarticular brucellosis oscillates between $33 \%$ and $77 \%$ [3] . In the reviewed cases culture of synovial fluid sample or tissue sample recovered brucella in 17 cases (85\%).In one case the germe was isolated from a sinus tract discharge [28] and from blood samples in two cases $[\underline{18}, \underline{23}]$. Laboratory culture of brucella is often unsuccessful because of the slow-growing nature of these microorganisms and the requirement for special media and high $\mathrm{Co} 2$ tension. So the culture period should be made longer than usual and clinicians should notify the laboratory staff if there is a suspicion of brucellosis [29]. Negative joint culture result does not rule out osteoarticular brucellosis and the diagnosis can be made through the detection of specific antibodies in serum. In active brucellosis, high titers of IgM antibodies can be detected by standard agglutination and Rose Bengal tests, which are followed by an increase of $\operatorname{IgG}$ and $\operatorname{IgA}$ antibodies in chronic stage of the disease [30]. In our review 18 patients $(90 \%)$ had positive titers of specific antibodies $(>=80)$. Generally joint prothesis can become infected through three different routes: Implantation, hematogenic infection, and reactivation of latent infection [31]. In Brucellar PJI most of the authors support the hematogenous route [려]. Previous spinal brucellosis in our patient supports this septic pathogenesis of the articular involvement. Because of the rare occurrence of PJI caused by Brucella, there is no consensus on its management. The most accepted course is antibiotic treatment with removal or retention of prosthetic components [르] . A variety of drugs have activity against brucella, however the results of in vitro susceptibility tests do not always predict clinical efficacy [32].The intracellular localization of brucella is believed to offer some protection against antimicrobials, and drugs with good penetration into cells are thought necessary for cure. Monotherapy for brucellosis has generally been considered inadequate due to unacceptably high relapse rate. Of the 20 cases that we reviewed, 14 were treated with double antibiotic therapy $[\underline{16}-\underline{18}, \underline{20}-\underline{23}, \underline{25}-\underline{28}]$, the most used association was Doxycylline and Rifampicine (8 cases) this association offers the advantage of an all-oral treatment and was recommended by the World Health Organization (WHO) in 1986 [33] and by Consensus "Loannina Recommendations" for 
Table1: Summuary of the reported cases in the literature

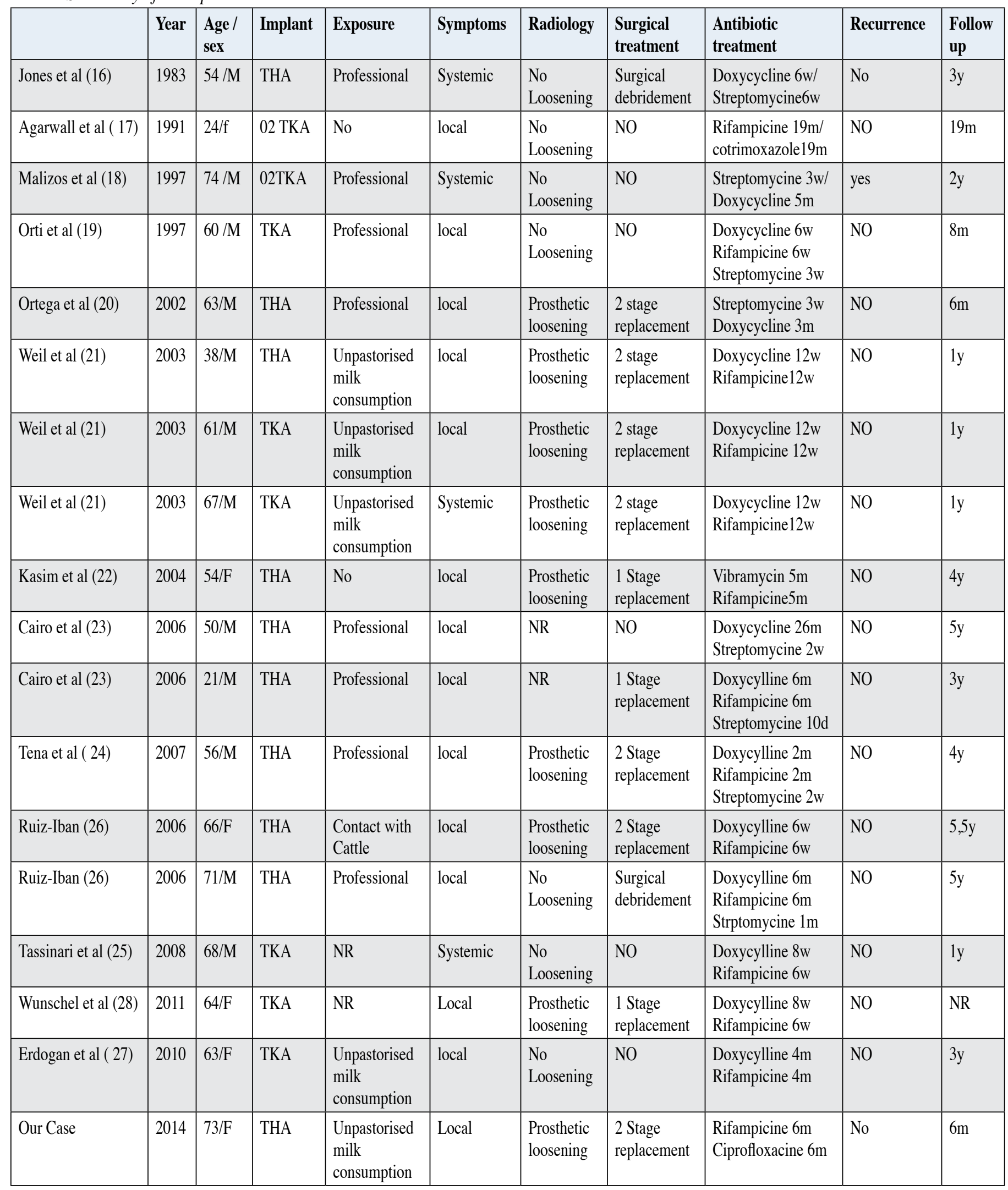

$\mathrm{M}=$ Male, $\mathrm{F}=$ Female $; \mathrm{TKA}=$ Total Knee arthroplasty, THA= Total Hip arthroplasty $; \mathrm{y}=$ years, $\mathrm{m}=$ Months, w= Weeks, 
the Treatment of Human Brucellosis in 2006 [34] . The most used antibiotics are Doxycyclline in 15 cases, Rifampicine in 14 cases, Streptomycine in 8 cases, Vibramicyne in 1 case, cotrimoxasole in 1 case and ciprofloxacine in 1 case. In our patient, because of the digestive disagreement, we used flouroquinolone which is considered as an acceptable alternative to doxycycline [34]. The total duration of antibiotic therapy necessary for eradication of the infection is unknown. In the review antibiotic treatment lasted from 6 weeks to a maximum of 26 months. Six Weeks is the duration recommended by the WHO and the Loannina Consensus. In six cases out of twenty the infection resolved with the sole use of the antibiotic therapy without having to resort to surgical revision $[\underline{17}, \underline{18}, \underline{19}, \underline{23}, \underline{25}, \underline{27}]$ in this patient there was no radiographic evidence of implant loosening. A single stage prosthetic revision was done in 3 cases but only because the infection had not been suspected from the beginning $[\underline{22}, \underline{23}, \underline{28}]$. In 7 cases a two stages revision was done, this procedure is believed to be the treatment ofchoice for loosened total joint arthroplasty infected with brucella. In brucellosis, even with effective drug treatment, relapses occur in 5-10\% of patients, usually in the early post-treatment period [34], in our review the infection was recurrent in only one patient out of twenty [18].

\section{Conclusions}

Brucella should be evocated as a cause of total joint arthroplasty infection especially in patients from endemic regions and with occupational exposure. Antibiotic treatment alone can be followed if there are no signs of implant loosening. Tow stage revision should be considered in other cases.

\section{Disclosure}

The authors declare that there is no conflict of interest regarding the publication of this paper. For full disclosures refer to last page of this journal.

\section{References}

1. Corbel MJ. Brucellosis: an overview. Emerg Infect Dis. 1997;3:213-2.

2. Pappas G, Akritidis N, Bosilkovski M, Tsianos E. Brucellosis. N Engl J Med. 2005;352: 2325-36.

3. Mousa AR, Muhtaseb SA, Almudallal DS, Khodeir SM, Marafie AA. Osteoarticular complications of brucellosis: a study of 169 cases. Rev Infect Dis. 1987;9:53143.

4. Rote-Querol J. Osteo-articular sites of brucellosis. Ann Rheum Dis.1957;16:63-8.

5. Ariza J, Gudiol F, Valverde J et al. Brucellar spondylitis: a detailed analysis based on current findings. Rev Infect Dis. 1985;7:656-64.

6. Ariza J, Pujol M, Valverde J et al. Brucellar sacroiliitis: findings in 63 episodes and current relevance. Clin Infect Dis. 1993;16:761-5.
7. Gonzalez-Gay MA, Garcia-Porrua C, Ibanez D, Garcia-Pais MJ. Osteoarticular complications of brucellosis in an Atlantic area of Spain. J Rheumatol.1999;26:141-5.

8. Gotuzzo E, Alarcon GS, Bocanegra TS et al. Articular involvement in human brucellosis: a retrospective analysis of 304 cases. Semin Arthritis Rheum. 1982;12:245-55.

9. Khateeb MI, Araj GF, Majeed SA, Lulu AR. Brucella arthritis: a study of 96 cases in Kuwait. Ann Rheum Dis. 1990;49:994-8.

10. Solera J, Lozano E, Martinez-Alfaro E et al. Brucellar spondylitis: review of 35 cases and literature survey. Clin Infect Dis. 1999;29:1440-9.

11. Zaks N, Sukenik S, Alkan M et al. Musculoskeletal manifestations of brucellosis: a study of 90 cases in Israel. Semin Arthritis Rheum. 1995;25:97-102.

12. Lentino JR. Prosthetic joint infections: bane of orthopedists, challenge for infectious disease specialists. Clin Infect Dis. 2003;36(9):1157-61.

13. Blom AW, Brown J, Taylor AH, et al. Infection after total knee arthroplasty. J Bone Joint Surg Br. 2004;86(5):688-91.

14. Blom AW, Taylor AH, Pattison G, et al. Infection after total hip arthroplasty: The Avon experience. J Bone Joint Surg Br. 2003; 85(7):956-9.

15. Zimmerli W, Trampuz A, Ochsner PE. Prosthetic-joint infections. N Engl J Med. 2004;351(16):1645-54.

16. Jones RB, Smith J, Hofmann A, Rogers D. Secondary infection of a total hip replacement with Brucella abortus. Orthopedics. 1983;6:184-6.

17. Agarwall S, Kadhi SKM, Rooney RJ. Brucellosis complicating bilateral knee arthroplasty. ClinOrthop. 1991;267:179-81.

18. Malizos KN, Makris CA, Soucacos PN. Total knee arthroplasties infected by Brucella melitensis: case report. Am J Orthop. 1997;26:283-5.

19. Orti A, Roig P, Alcala R, et al. Brucellar prosthetic arthritis in a total knee replacement. Eur J Clin Microbiol Infect Dis. 1997;16:843-5.

20. Ortega M, Rodriguez EC, Aguera M. Brucellosis as a cause of septic loosening of total hip arthroplasty. J Arthrop. 2002;17:384-7.

21. Weil Y, Mattan Y, Liebergall M, Rahav G. Brucella prosthetic joint infection: a report of 3 cases and review of the literature. Clin Infect Dis. 2003;36:81-6.

22. Kasim RA, Araj GF, Afeiche NE, Tabbarah ZA. Brucella infection in total hip replacement: case report and review of the literature. Scand J Infect Dis. 2004;36:65-7.

23. Cairo M, Calbo E, Gomez L at al. Foreign-body osteoarticular infection by Brucella melitensis. J Bone Joint Surg. 2006;88:202-4.

24. Tena D, Romanillos O, Rodríguez-Zapata $\mathrm{M}$ at al. Prosthetic hip infection due to Brucella melitensis: case report and literature review. Diagn Microbiol Infect Dis. 2007;58(4):481-5.

25. Tassinari E, Di Motta D, Giardina F, Traina F, De Fine M, Toni A. Brucella infection in total knee arthroplasty. Case report and revision of the literature. Chir Organi Mov. 2008;92(1):55-9.

26. Ruiz-Iban MA, Crespo P, Diaz-Peletier R, Rozado AM, Lopez-Pardo A. Total hip arthroplasty infected by Brucella: a report of two cases. J OrthopSurg. 2006;14(1):99-103

27. Erdogan H, Cakmak G, Erdogan A, Arslan H. Brucella melitensis infection in total knee arthroplasty: a case report. Knee Surg Sports Traumatol Arthrosc. 2010;18(7):908-10.

28. Wünschel M, Olszowski AM, Weissgerber P, Wülker N, Kluba T. Chronic brucellosis: a rare cause of septic loosening of arthroplasties with high risk of laboratoryacquired infections. Z OrthopUnfall. 2011;149(1):33-6.

29. Franco MP, Mulder M, Gilman RH, Smits HL. Human brucellosis. Lancet Infect Dis. 2007;7:775-86.

30. Sanchez-Sousa A, Torres C, Campello MG at al. Serological diagnosis of neurobrucellosis. J Clin Pathol. 1990;43:79 - 81.

31. Del Pozo I.L., Patel R. Infection associated with prosthetic joints, N Engl J Med. 2009;361(8):787-794.

32. Corbel MJ. Brucellosis in Humans and Animals. Geneva: World Health Organization, 2006.

33. Joint FAO-WHO expert committee on brucellosis. World Health Organ Tech Rep Ser. 1986;740:1-132.

34. Ariza J, Bosilkovski M, Cascio A et al. Perspectives for the treatment of brucellosis in the 21st century: the Ioannina recommendations. PLoS Med. 2007;4:317. 